\title{
Augustus Waller and the case of the disappearing axon
}

\author{
John W Griffin
}

You will be familiar with the British 'locked room' mystery genre: something of great value disappears from a locked room in a stately home. The question is how the trick was done, and the answer is certain to be unveiled in the book's final chapter. Imagine a variation on this theme. The bridge on the only road leading to the house fails. The house's inhabitants depend on the road for vital supplies, but emails from the house suggest that all is well, until one day communication abruptly ceases. When investigators reach the site, the stately home and its inhabitants have disappeared.

This outline is analogous to the great mystery framed by the British writer Augustus Waller in 1858. We'll call it 'The Case of the Disappearing Axon'. He recognized that when a nerve fiber is severed the distal stump lingers for several days, cut off from the proximal stump but apparently unchanged and electrically competent. Then, it abruptly-explosively-disappears. How is the trick done? We now know that the axon has only a modest repertoire of local protein synthesis. Instead, it depends largely on materials synthesized in the nerve cell body and delivered by axonal transport. Wallerian degeneration is not, however, merely deprivation of axonally transported materials. Rather, it is an active process of destruction, as confirmed by the discovery of the Wallerian degeneration slow $\left(\right.$ WId $\left.{ }^{S}\right)$ mouse. In this spontaneous mutant, the breakdown of the distal stump axon is markedly delayed, indicating that the axon is capable of prolonged survival. We know that the final events in the sequence of Wallerian degeneration involve entry of extracellular calcium and release of intracellular calcium stores, with consequent activation of calcium-dependent proteases. We do not, however, understand the early events.

This case has high stakes, as axonal degeneration is arguably the most frequent neuronal pathology.
... axonal

degeneration

is arguably the

most frequent

neuronal

pathology

JW Griffin is the Editor-in-Chief of Nature Clinical Practice Neurology.

\section{Competing interests}

The author declared he has no competing interests.

www.nature.com/clinicalpractice doi:10.1038/ncpneuro0550
Axons are interrupted in diseases as diverse as stroke, transverse myelitis and trauma. Even more prevalent are chronic axonal degenerations of the type seen in most peripheral neuropathies, in a variety of degenerative diseases (for example, Friedreich's ataxia), and even in the late sequelae of multiple sclerosis. Most of these degenerations share pathological features with axonal interruption, and are appropriately called Wallerian-like degenerations.

The controversy over the nature of the change responsible for generating the WId ${ }^{s}$ mouse phenotype frames the issue of Wallerian degeneration. Wld is a chimeric fusion protein that includes components of the ubiquitin pathway and an NAD salvage pathway. Even if the causal mutation is localized to the latter region of the protein, there remain at least two camps with strongly held views. One argues that the effect of the mutation is on energy metabolism at the level of the axon. The other places the change at the level of the nucleus, with increased expression of the transcription factor Sirt1, and consequent changes in gene expression that make the axon less vulnerable.

We can anticipate an answer to the WId ${ }^{s}$ mystery soon, as the mutant allele has recently been expressed in fruit flies. The power of fly genetics, and the relatively rapid phenotypic readout, will allow dissection of the causal element of the WId ${ }^{s}$ chimera with a speed that mouse geneticists can only envy.

Understanding Wallerian degeneration should afford the potential to prevent axonal loss in monophasic neurotoxic injuries associated with cancer or HIV chemotherapies, and to slow axonal loss in diseases in which the axon degenerates in continuity, such as diabetic neuropathy. Make no mistake-the final chapters of Waller's great mystery will have a rapt audience. 